Article

\title{
L-Glutamine Attenuates Apoptosis Induced by Endoplasmic Reticulum Stress by Activating the IRE1 $\alpha$-XBP1 Axis in IPEC-J2: A Novel Mechanism of L-Glutamine in Promoting Intestinal Health
}

\author{
Qian Jiang 1,2 (D), Jiashun Chen ${ }^{1,3}$, Shaojuan Liu ${ }^{1,2}$, Gang Liu 1,3,* (D), Kang Yao 1,3,4,* and \\ Yulong Yin 1,3,4 \\ 1 Key Laboratory of Agroecological Processes in Subtropical Region, Institute of Subtropical Agriculture, \\ Chinese Academy of Sciences, National Engineering Laboratory for Pollution Control and Waste Utilization \\ in Livestock and Poultry Production, Changsha 410125, China; jiangqianisa@gmail.com (Q.J.); \\ chenjiashun1988@163.com (J.C.); liushaojuan15@mails.ucas.ac.cn (S.L.); yinyulong@isa.ac.cn (Y.Y.) \\ 2 University of the Chinese Academy of Sciences, Beijing 10008, China \\ 3 College of Animal Science and Technology, Hunan Agricultural University, Changsha 410125, China \\ 4 Hunan Co-Innovation Center of Animal Production Safety, CICAPS, Changsha 410128, China \\ * Correspondence: gangle.liu@gmail.com (G.L.); yaokang@isa.ac.cn (K.Y.); \\ Tel.: +86-731-461-5204 (G.L.); +86-731-8461-9767 (K.Y.)
}

Received: 31 October 2017; Accepted: 1 December 2017; Published: 5 December 2017

\begin{abstract}
Intestinal absorption and barrier malfunctions are associated with endoplasmic reticulum stress (ERS) in the intestine. We induced ERS by exposing the intestinal porcine epithelial cell line J2 (IPEC-J2) to tunicamycin (TUNI) to explore the potential of L-glutamine to reduce ERS-induced apoptosis. Our experiments demonstrated that exposing cells to TUNI results in spontaneous ERS and encourages the upregulation of glucose-regulated protein 78 (GRP78). Prolonged TUNI-induced ERS was found to increase apoptosis mediated by $\mathrm{C} /$ enhancer binding protein homologous protein (CHOP), accompanied by GRP78 downregulation. Treatment with L-glutamine was found to promote cell proliferation within the growth medium but to have little effect in basic Dulbecco's modified Eagle medium. Finally, in the milieu of TUNI-induced ERS, L-glutamine was found to maintain a high level of GRP78, alleviate CHOP-mediated apoptosis and activate the inositol requiring enzyme $1 \alpha$ (IRE1 $\alpha$ )-X-box binding protein 1 (XBP1) axis. A specific inhibitor of the IRE1 $\alpha$-XBP1 axis reversed the protective effect of L-glutamine by blocking the expression of IRE1 $\alpha / \mathrm{XBP} 1 \mathrm{~s}$. We propose that the functional effect of L-glutamine on intestinal health may be partly due to its modulation of ERS and CHOP-mediated apoptosis.
\end{abstract}

Keywords: endoplasmic reticulum stress; IRE1 $\alpha$-XBP1; L-glutamine; intestinal porcine epithelial cell line J2

\section{Introduction}

The amino acid L-glutamine is considered to be the carbon source for purine and pyrimidine synthesis. It participates in the Coriolis cycle through deamination and related procedures [1], and becomes essential when the body suffers from metabolic stresses such as trauma [2], cancer [3], sepsis [4], or burns [5]. It is vital to ensure the intake of L-glutamine to meet the increased physiological needs arising from these conditions. Specifically, L-glutamine has received considerable attention in animal research for its health-promoting properties. For example, a supplement of L-glutamine administered to weaning piglets modified immune cells in the mesenteric lymph nodes and supported a $\mathrm{T}$ helper 1 type cytokine response after $\mathrm{T}$ cell stimulation [6]. In vitro, L-glutamine deficiency 
disturbs amino acid metabolism in intestinal epithelial cells [7], attenuates their mammalian target of rapamycin (mTOR) pathway [8] and downregulates mitogen-activated protein kinase/extracellular signal-regulated kinase signalling, thereby inhibiting protein synthesis and cell proliferation [9].

The endoplasmic reticulum (ER) is responsible for polypeptide synthesis, post-translational modification and folding to form proteins for cellular functions or secretion [10]. ER stress (ERS) is caused by the excessive accumulation of misfolded and unfolded proteins in the intestinal organs during protein biosynthesis [11]. Intestinal absorption and barrier malfunctions have been attributed to ERS [12-14]. Such stress triggers a series of signalling and transcriptional events known as the unfolded protein response (UPR) [15]. The enhanced UPR is triggered to maintain ER homeostasis in cells; its failure can lead to local inflammation in stressed cells and programmed cell death via apoptosis [16] or autophagy [17]. UPR activation of the IRE1 $\alpha$-XBP1 branch has shown to be involved in cell homeostasis and survival [18]. Similarly, research [19] has indicated that L-glutamine treatment attenuates ERS and apoptosis in 2,4,6-trinitrobenzenesulfonic acid (TNBS) induced colitis in rats. Compared with rats, pigs experience fiercer ERS as a consequence of pathogen infection [20] and digestive difficulties [21]. Although the health-promoting properties of L-glutamine in porcine intestine have been acknowledged, the molecular mechanisms underlying the regulation of ERS by L-glutamine are still poorly understood.

The intestinal porcine epithelial cell line J2 (IPEC-J2), originally isolated from the jejunal epithelium of a neonatal unsuckled piglet [22], offers a realistic and representative means of mimicking porcine small intestine and provides a useful cell model for pharmacology research as well as studies of toxicity [23], microbiology [24], bioavailability [25], and metabolism [26] in the fields of veterinary medicine and animal science.

In the study reported here, we selected IPEC-J2 as the cell model to cast new light on the role of L-glutamine in responding to ERS, and its molecular mechanism.

\section{Results}

\subsection{Role of Tunicamycin (TUNI) in Spontaneous Endoplasmic Reticulum Stress (ERS)}

The UPR pathway is regularly triggered by ERS in the intestinal epithelium, and several reports have suggested that inflammatory bowel disease is involved in the induction of ERS. Specifically, activating transcription factor 6 (ATF6), ATF4 and spliced XBP-1 (XBP-1s) can regulate the expression of ER chaperone proteins that enhance ER folding ability, including glucose-regulated protein 78 (GRP78) and other stress genes, such as C/enhancer binding protein homologous protein (GADD153/CHOP). In the study reported here, we first used the TUNI-induced ERS model with IPEC-J2 to examine the potential role of TUNI in ERS signalling and ERS-mediated apoptosis. IPEC-J2 was treated with $1 \mu \mathrm{g} \mathrm{mL}^{-1}$ TUNI for $0,8,16,24$, or $48 \mathrm{~h}$, and cell viability was assessed using the Cell Counting Kit 8 (CCK-8), as shown in Figure 1A. Based on our pre-experiments, $24 \mathrm{~h}$ treatment with $1 \mu \mathrm{g} \mathrm{mL}^{-1}$ TUNI was selected as the prolonged ERS cell model. Immunofluorescence analysis was performed to detect GRP78 levels (Figure 1F). The expression of GRP78, cleaved caspase-3 and GADD153/CHOP was evaluated using the Western blot (Figure 1B). As shown, TUNI was found to encourage the upregulation of GRP78 (Figure 1D,F) and increase the expression of GADD153/CHOP (Figure 1C) and cleaved caspase-3 (Figure 1E), indicating that spontaneous ERS and ERS-mediated cell apoptosis had been triggered in this cell model. 
A
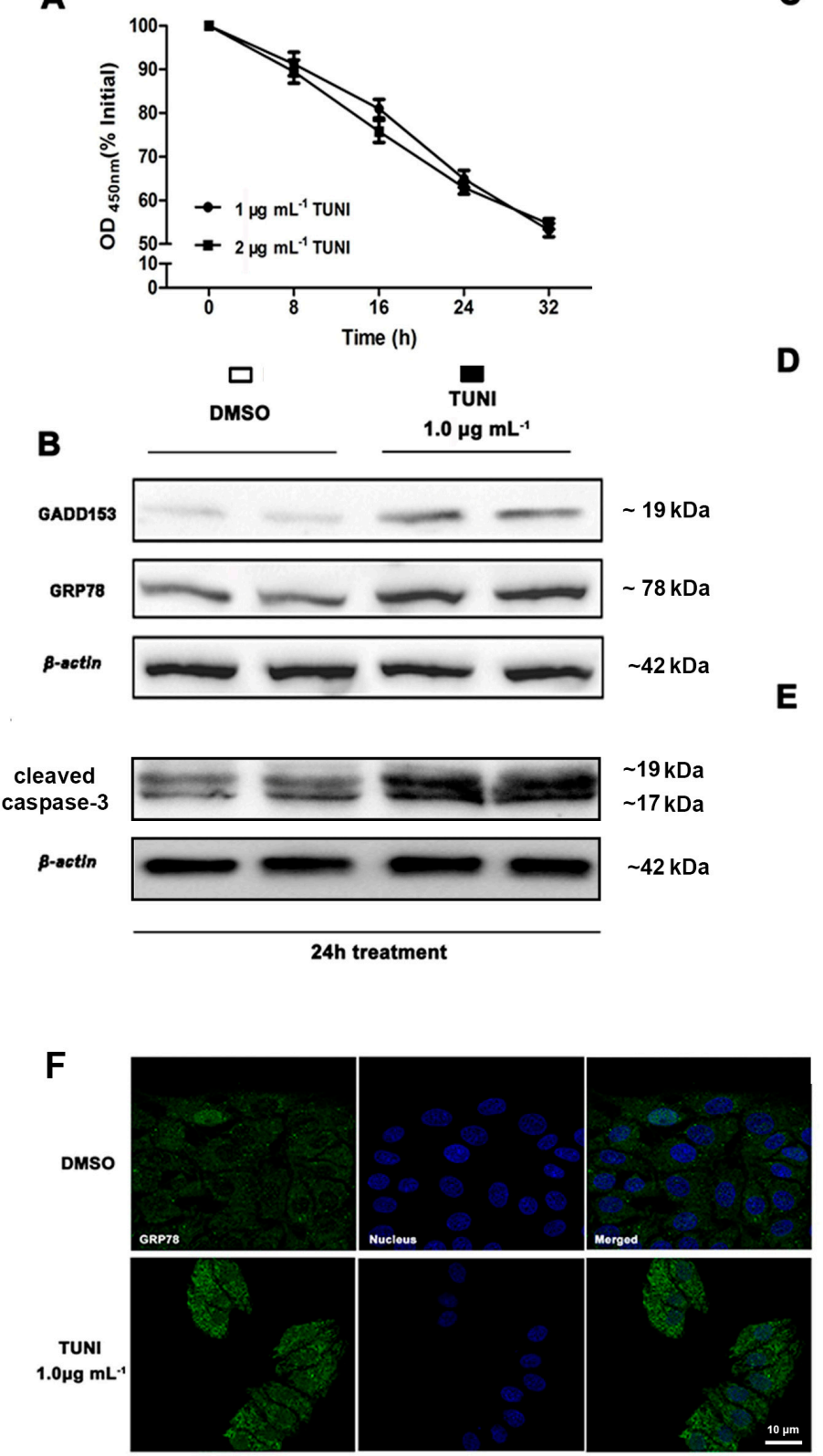

Basic DMEM without GIn or FBS / 24h treatment
C

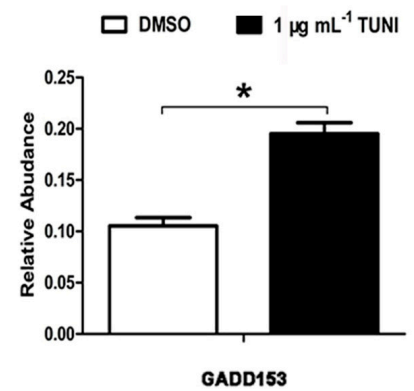

D

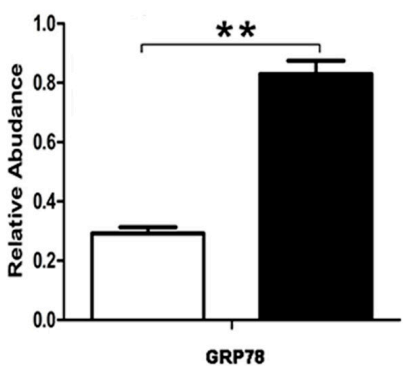

$\mathbf{E}$
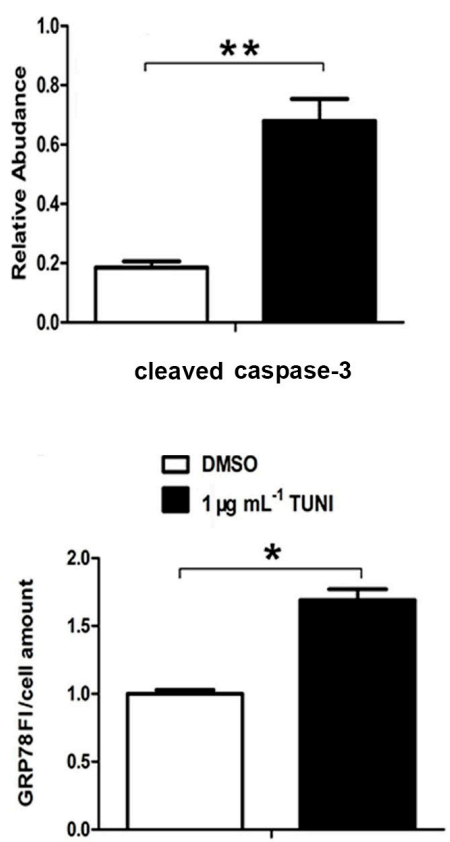

Figure 1. TUNI-induced (tunicamycin) endoplasmic reticulum stress (ERS) in intestinal porcine epithelial cell line J2 (IPEC-J2). (A) Cell viability assay performed using Cell Counting Kit 8 (CCK-8) after cells had been treated with $1.0 \mu \mathrm{g} \mathrm{mL} \mathrm{mL}^{-1}$ TUNI for 0 to $32 \mathrm{~h}$; (B) western blot analysis of ERS mark proteins after ERS induction; two representative protein bands from the three independent experiments are shown; (C,D) relative abundance of GRP78 and GADD153; (E) fluorescence staining of GRP78 in cells treated with dimethyl sulphoxide (DMSO) or TUNI $\left(1 \mu \mathrm{g} \mathrm{mL} \mathrm{m}^{-1}\right)$ for $24 \mathrm{~h}$. Data given as means \pm standard deviations (SDs) for three independent experiments (* means under $T$ test, $p<0.05,{ }^{* *}$ means under $T$ test, $p<0.01)$.

\subsection{L-Glutamine Promotes Cell Proliferation in Normal Growth Medium}

To clarify the sole effect of L-glutamine on cell survival, we treated IPEC-J2 with L-glutamine in a normal growth medium (dulbecco's modified eagle medium with 10\% foetal bovine serum, FBS) and basic dulbecco's modified eagle medium without $10 \%$ FBS), respectively. In the normal growth 
medium, cell cycle distribution was determined by flow cytometry (Figure 2E), and proliferation was observed by 5-ethynyl-2'-deoxyuridine (EdU) staining (Figure 2C). In the normal growth medium, L-glutamine treatment was found to improve cell viability (Figure 2A,D) and promote cell proliferation, as indicated by enhanced DNA replication (Figure 2C) and an increased number of cells in the S-phase (Figure 2E,F). However, in the basic DMEM, L-glutamine improved cell viability only for the first $16 \mathrm{~h}$; this tendency receded over the following $16 \mathrm{~h}$ (Figure 2B).

A

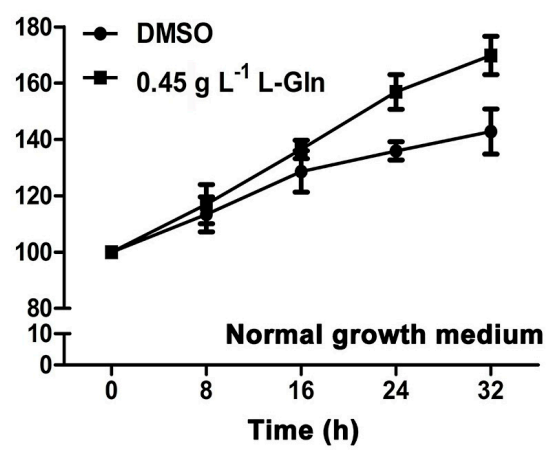

\section{C}

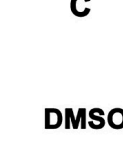

$0.45 \mathrm{~g} \mathrm{~L}^{-1}$
$\mathrm{~L}-\mathrm{G} \ln$
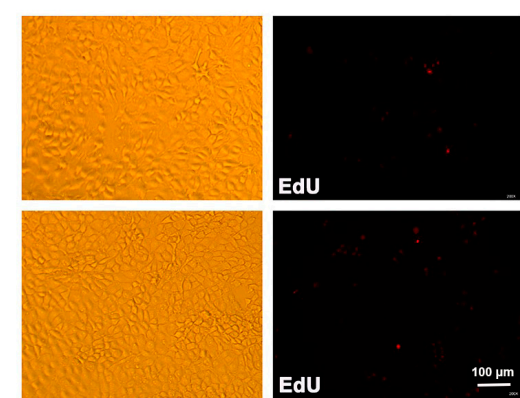

Normal growth medium (24 h)

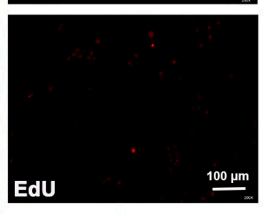

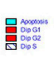
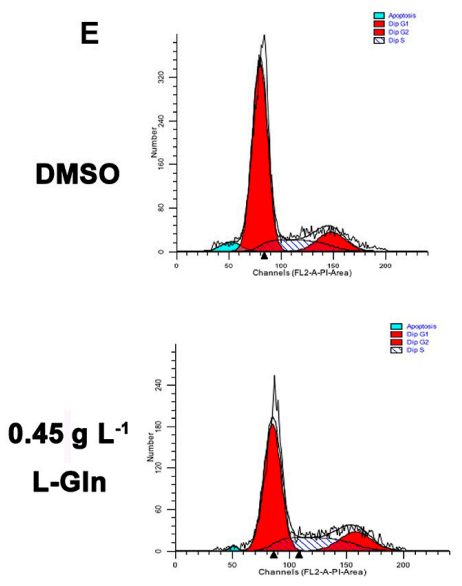
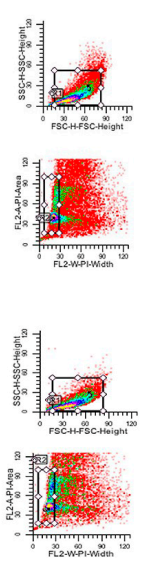

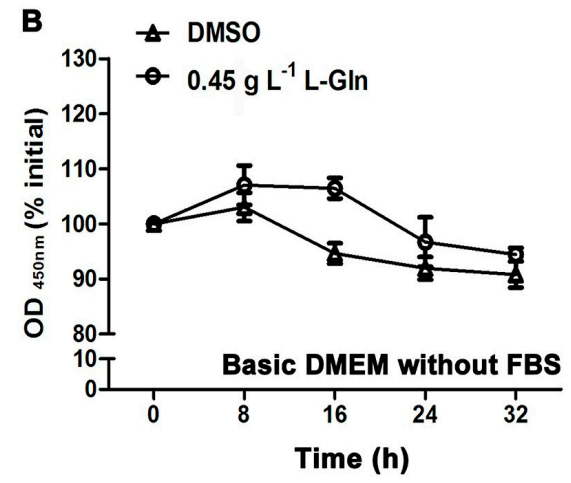

D

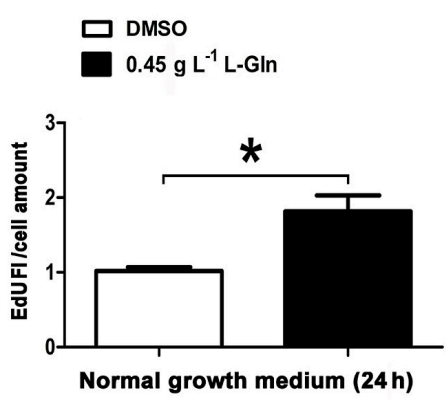

$\mathbf{F}$

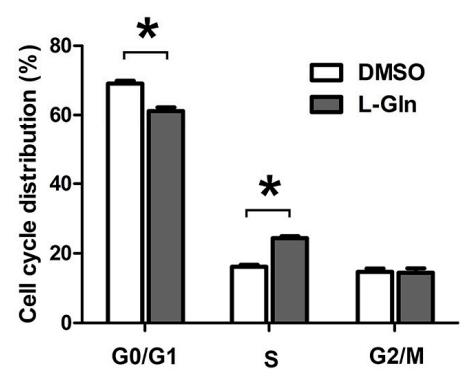

Figure 2. L-glutamine promotes cell proliferation within specific milieu. (A) In the normal growth medium, cells were treated with DMSO or $0.45 \mathrm{~g} \mathrm{~L}^{-1}$ L-glutamine for 0 to $32 \mathrm{~h}$, followed by a cell viability assay using CCK-8; (B) In basic DMEM, relative cell viability was measured using CCK-8 after treating cells with DMSO or $0.45 \mathrm{~g} \mathrm{~L}^{-1}$ L-glutamine for 0 to $32 \mathrm{~h}$; (C,D) After the treatment described in $\mathrm{A}$, cell proliferation rate was determined by EdU staining, and the results are shown as relative EdU fluorescent light/cell values; (E,F) After the treatment described in A, cell cycle distribution was determined by flow cytometry; the statistical results are shown here. Data given as means $\pm \mathrm{SDs}$ for the three independent experiments ( ${ }^{*}$ means under $T$ test, $p<0.05,{ }^{* *}$ means under $T$ test, $p<0.01$ ). 


\subsection{L-Glutamine Reduces Apoptosis and Maintains a High Level of GRP78 in Response to ERS}

To determine whether L-glutamine regulated ERS and ERS pathway mediated apoptosis in the basic DMEM, we treated cells with DMSO, L-glutamine $\left(0.45 \mathrm{~g} \mathrm{~L}^{-1}\right)$ and TUNI $\left(1 \mu \mathrm{g} \mathrm{mL}{ }^{-1}\right)$ or a combination of L-glutamine and TUNI for different durations $(0,8,16,24$, and $36 \mathrm{~h})$. The results of a cell viability assay using the CCK-8 revealed the survival-promoting effect of L-glutamine in response to TUNI-induced ERS (Figure 3A). This finding was consistent with the results determined by Annexin V-FITC flow cytometry analysis, which showed that ERS-induced apoptosis was attenuated by L-glutamine (Figure 3B,C). To further clarify the anti-apoptotic effect of L-glutamine, we compared GRP78 expression between the TUNI group and the L-glutamine-TUNI group during the initial ERS response ( $8 \mathrm{~h}$ treatment) and the prolonged ERS response ( $24 \mathrm{~h}$ treatment) using immunofluorescence (Figure 3D) and the Western blot (Figures 3E and 4E). We observed that GRP78 expression was not affected by L-glutamine during the initial ERS response, but that L-glutamine maintained a relatively high level of GRP78 during the prolonged ERS response (Figure 3F,G).

A

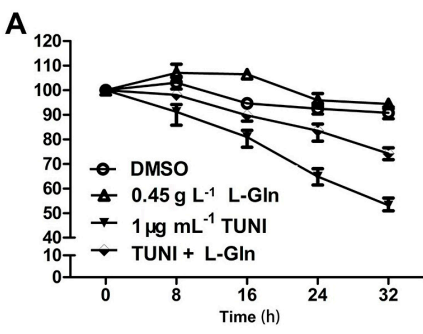

B

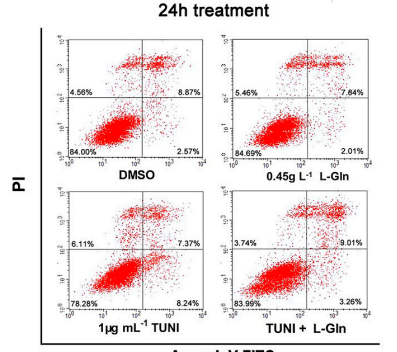

C

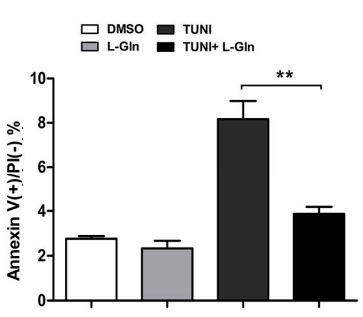

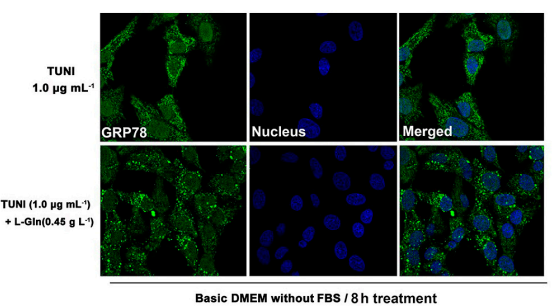

E

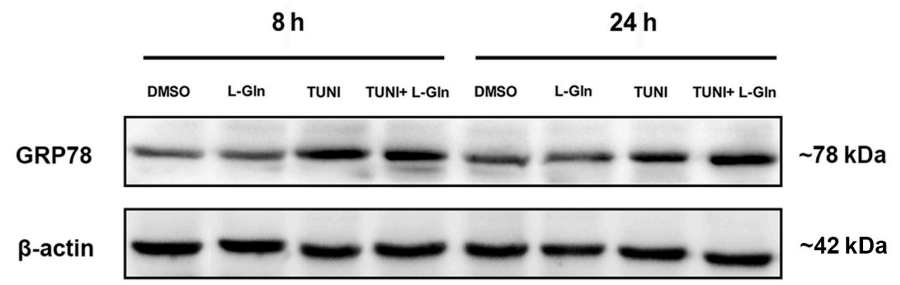

$\mathbf{F}$

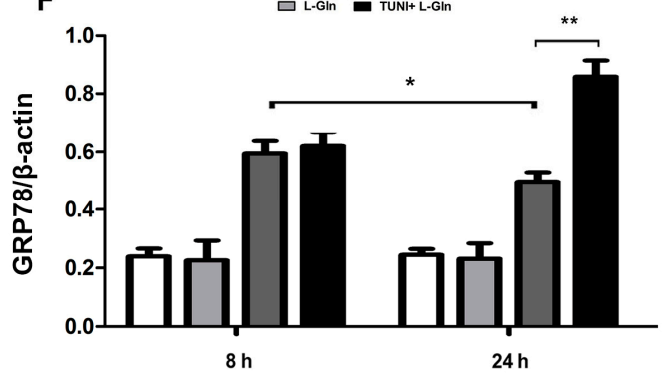

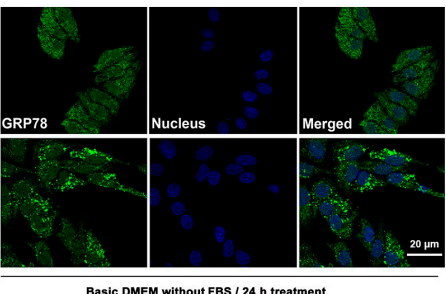

Basic DMEM without FBS $24 \mathrm{~h}$ treatment

$24 \mathrm{~h}$

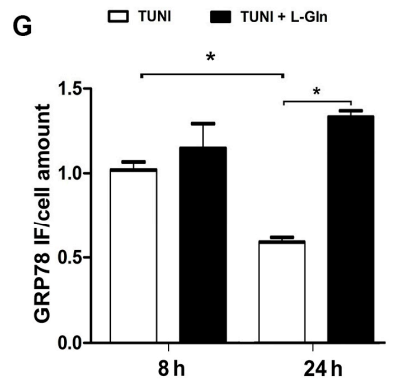

Figure 3. L-glutamine protects cell from TUNI-induced apoptosis. In basic DMEM, cells were treated with DMSO, $0.45 \mathrm{~g} \mathrm{~L}^{-1}$ L-glutamine and $1.0 \mu \mathrm{g} \mathrm{mL}^{-1}$ TUNI or a combination of L-glutamine and TUNI for 0 to $32 \mathrm{~h}$. (A) Relative cell viability was measured using CCK-8; (B) PI/Annexin V-FITC staining and cell fluorescent screening were performed by flow cytometry; (C) Statistical results of Annexin V(+)/PI(-) staining; (D) GRP78 and nucleuses of cells in 8 and $24 \mathrm{~h}$ treatments were fluorescence labelled with Alexa Fluor 488 and DAPI, and excitation fluorescence was captured by laser scanning confocal microscopy; (E) Western blot analysis of GRP78 protein after ERS induction for 8 or $24 \mathrm{~h}$; one representative protein band from the three independent experiments is shown; (F) Relative abundance of GRP78; (G) Relative fluorescence intensity of GRP78. Data given as means \pm SDs for the three independent experiments $\left({ }^{*}\right.$ means under $T$ test, $p<0.05,{ }^{* *}$ means under $T$ test, $\left.p<0.01\right)$. 

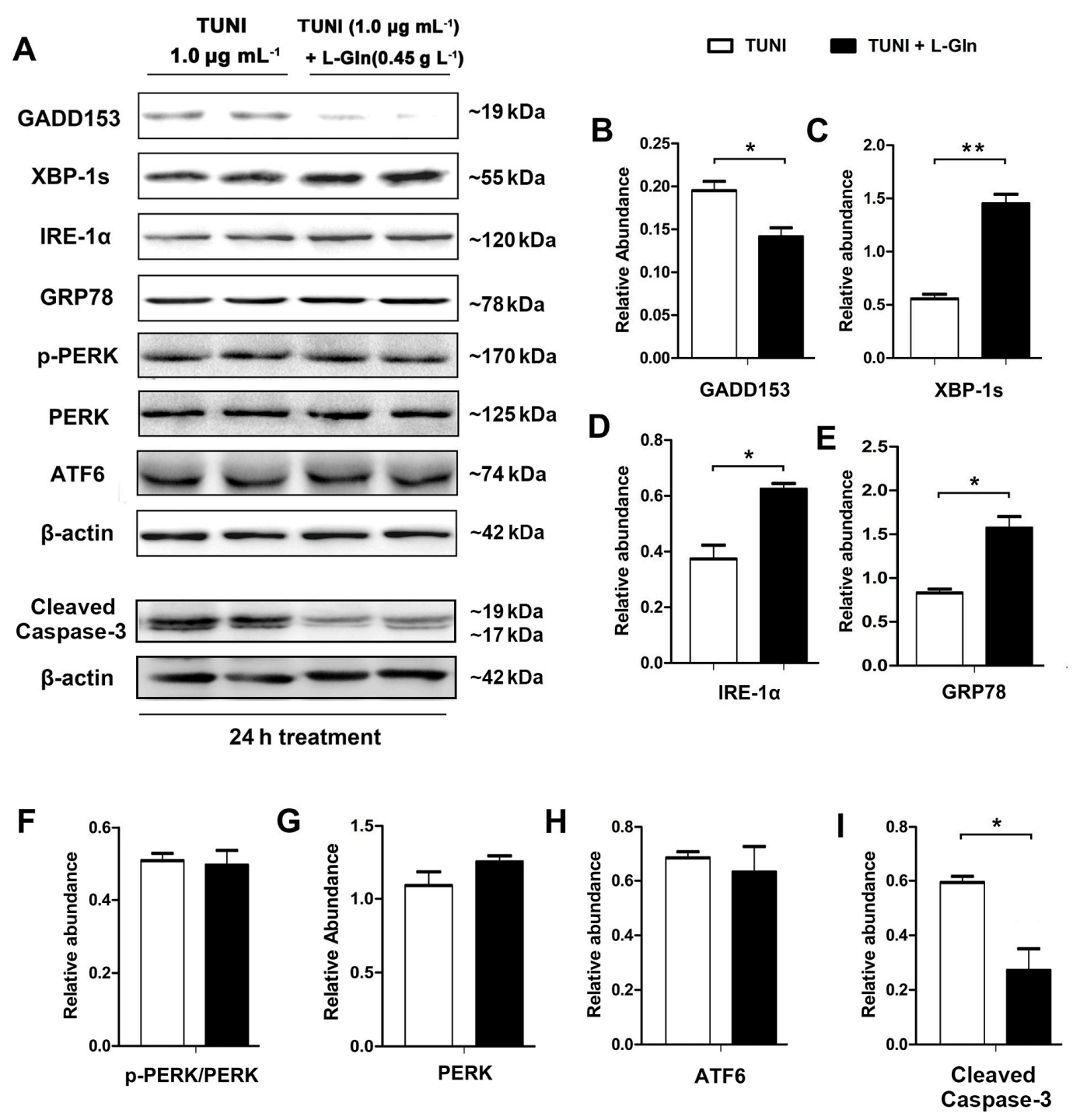

Figure 4. L-glutamine enhances IRE1 $\alpha$-XBP1 axis in ERS-responsive cells. In basic DMEM, cells were treated with $1.0 \mu \mathrm{g} \mathrm{mL}^{-1}$ TUNI or a combination of $0.45 \mathrm{~g} \mathrm{~L}^{-1}$ L-glutamine and TUNI for $24 \mathrm{~h}$. (A) Expression of unfolded protein response (UPR) pathway proteins and cleaved caspase-3, respectively, was determined using the Western blot; two representative protein bands from three independent experiments are shown; (B) Relative abundance of GADD153; (C) Relative abundance of XBP-1s; (D) Relative abundance of IRE-1 $\alpha$; (E) Relative abundance of GRP78; (F) Relative phosphorylation level of protein kinase RNA-like endoplasmic reticulum kinase (PERK) (phospho-PERK (p-PERK)/total PERK); (G) Relative abundance of total PERK; (H) Relative abundance of ATF6; (I) Relative abundance of cleaved caspase-3. $\beta$-actin was assessed as a loading control. Data given as means \pm SDs for the three independent experiments $\left({ }^{*}\right.$ means under $T$ test, $p<0.05$, ** means under $T$ test, $p<0.01$ ).

\subsection{L-Glutamine Alleviates C/Enhancer Binding Protein Homologous Protein (CHOP)-Mediated Apoptosis and Activates IRE1 $\alpha$-XBP1 Axis}

Next, to explore the mechanisms of the inhibition of cell apoptosis by L-glutamine, we treated the cells with DMSO, L-glutamine $\left(0.45 \mathrm{~g} \mathrm{~L}^{-1}\right)$, and TUNI $\left(1 \mu \mathrm{g} \mathrm{mL}{ }^{-1}\right)$ or a combination of L-glutamine and TUNI for $24 \mathrm{~h}$ and performed ERS pathway joint analysis using the Western blot (Figure 4A). As shown, L-glutamine had no effect on the PERK, p-PERK, or ATF-6 pathways in the ERS-responsive cells (Figure 4F-H). However, it downregulated the expression of GADD153/CHOP (Figure 4B) and 
triggered the upregulation of IRE- $1 \alpha$ and XBP-1s (Figure 4C,D). Meanwhile, the expression of cleaved caspase-3, an indicator of cell apoptosis, was reduced by L-glutamine (Figure 4I).

\subsection{IRE1 $\alpha$-XBP1 Inhibition Reverses Protective Effect of L-Glutamine}

To determine whether the L-glutamine-mediated IRE1 $\alpha$-XBP1 axis alleviates ERS-induced apoptosis, we treated IPEC-J2 with doxorubicin (DOX), a specific inhibitor of the IRE1 $\alpha$-XBP1 axis. As shown in Figure 5, DOX inhibited the activation of IRE- $1 \alpha$ and XBP-1 in a dose-dependent manner (Figure 5A-C), but had no effect on cell survival (Figure 5D). In addition, $5 \mu \mathrm{M}$ DOX reversed the anti-apoptotic effect of L-glutamine by blocking the expression of IRE1 $\alpha$ and XBP-1s, as shown in Figure 6.
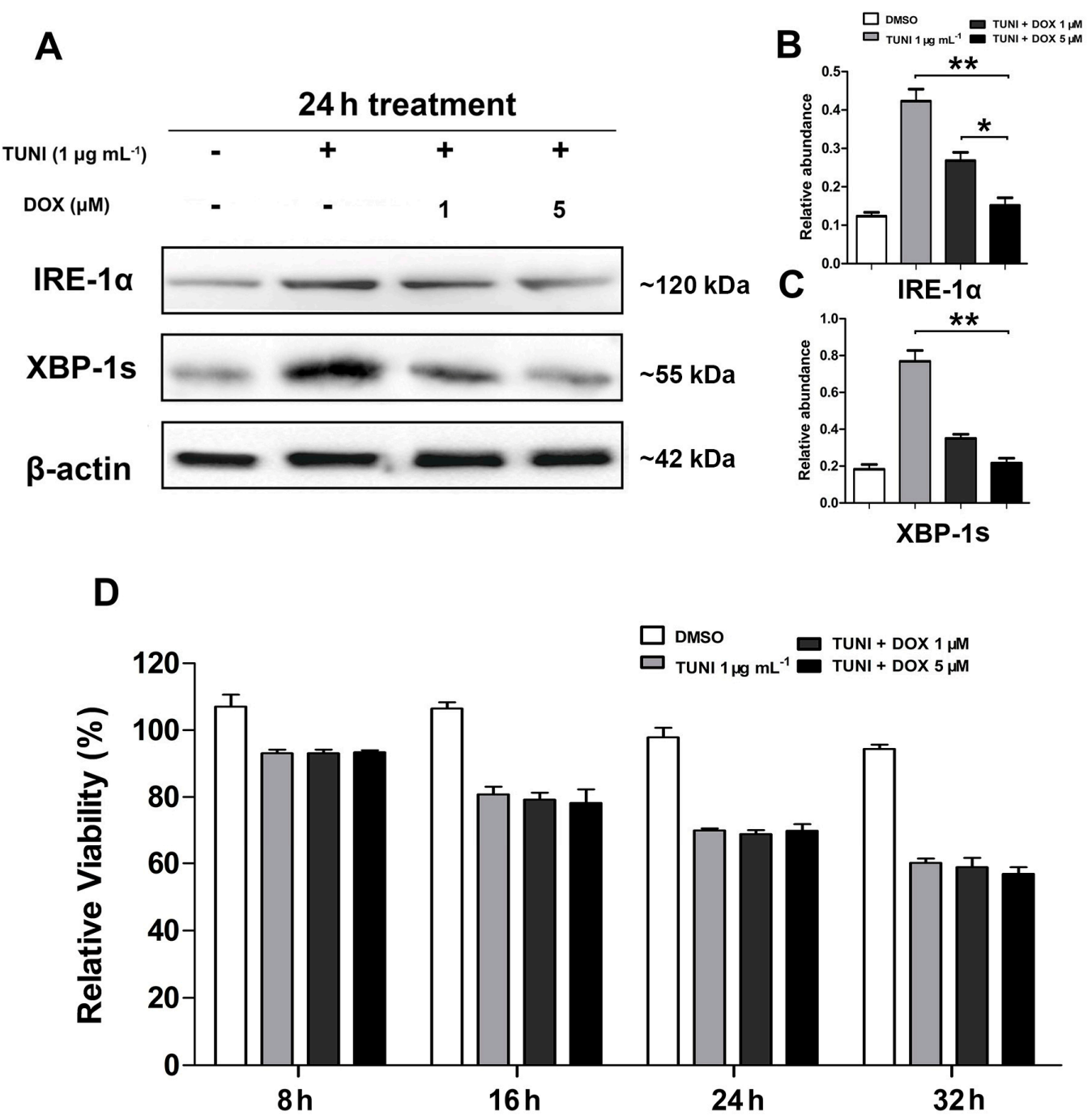

Figure 5. doxorubicin (DOX) inhibits activation of IRE- $1 \alpha$ and XBP-1. In basic DMEM, cells were treated with DMSO and $1.0 \mu \mathrm{g} \mathrm{mL}^{-1}$ TUNI or a combination of TUNI and DOX for $24 \mathrm{~h}$. (A) Expression of IRE- $1 \alpha$ and $\mathrm{XBP}-1$ s proteins was determined using the Western blot; one representative protein band from the three independent experiments is shown; (B) Relative abundance of IRE- $1 \alpha$; (C) Relative abundance of XBP-1s; (D) Relative cell viability was measured using CCK-8 after the treatment. $\beta$-actin was assessed as a loading control. Data given as means \pm SDs for the three independent experiments (* means under $T$ test, $p<0.05$, ${ }^{* *}$ means under $T$ test, $p<0.01$ ). 

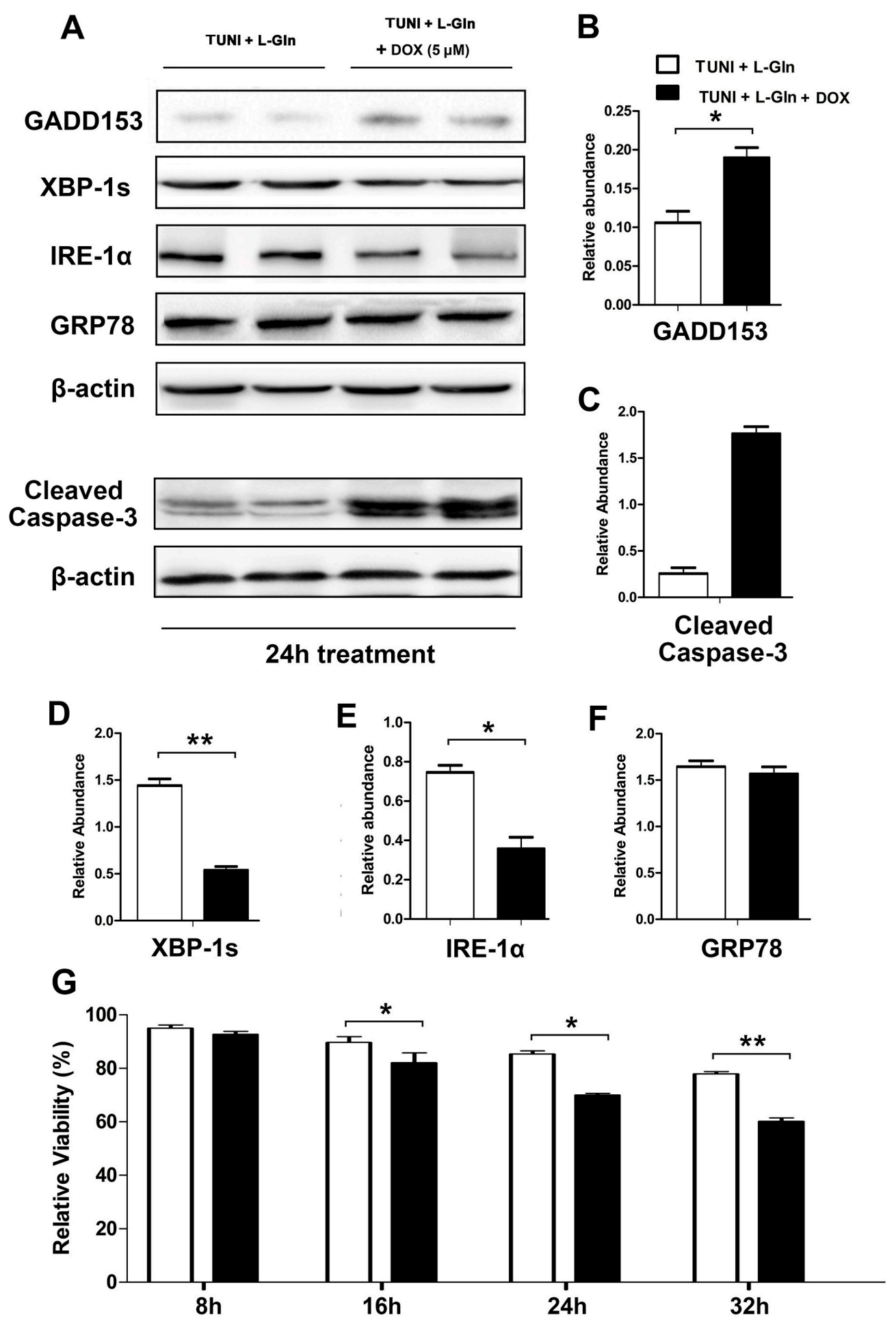

Figure 6. Inhibition of IRE- $1 \alpha$ and XBP-1 reverses the anti-apoptotic effect of L-glutamine. In basic DMEM, cells were treated with $1.0 \mu \mathrm{g} \mathrm{mL}^{-1} \mathrm{TUNI}$ and $0.45 \mathrm{~g} \mathrm{~L}^{-1}$ L-glutamine or a combination of TUNI, L-glutamine and $4 \mu \mathrm{M}$ DOX for $24 \mathrm{~h}$. (A) Expression of GADD153, IRE-1 $\alpha, \mathrm{XBP}-1 \mathrm{~s}$ and GRP78 proteins was measured using the Western blot; two representative protein bands from the three independent experiments are shown; (B) Relative abundance of GADD153; (C) Relative abundance of cleaved caspase-3; (D) Relative abundance of XBP-1s; (E) Relative abundance of IRE-1 $\alpha$; (F) Relative abundance of GRP78; (G) Relative cell viability was measured using CCK-8 after treatment. $\beta$-actin was assessed as a loading control, and data are given as the means \pm SDs for the three independent experiments $\left({ }^{*}\right.$ means under $T$ test, $p<0.05,{ }^{* *}$ means under $T$ test, $\left.p<0.01\right)$. 


\section{Discussion}

The structure and function of the small intestine in piglets change dramatically on exposure to various stress factors [27]. ERS is considered to be the basis for the progression of many intestinal diseases [21,28], and the health-promoting effect of L-glutamine in the intestine was verified many decades ago [29-31], but the precise regulatory mechanisms by which L-glutamine connects ERS with intestinal health are still poorly understood. This study is the first to reveal the role of L-glutamine in mediating ERS-induced cell apoptosis.

TUNI triggers stress by inhibiting the $N$-linked glycosylation of newly synthesised proteins in the ER [32]. This glycosylation controls both the process and the quality of folding [33]. GRP78 is recruited to bind to the unfolded proteins if the hydrophobic parts of the amino acid chain are not successfully buried in the protein interior [34]. Accordingly, researchers have reported that TUNI can induce ERS in various organs in a range of animal species [35-37]. However, only rarely have these studies focused on porcine intestinal cells. In the study reported here, TUNI induced the upregulation of GRP78 in IPEC-J2, indicating that ERS had been triggered. The upregulation of ER-colocalised GRP78 has been shown to help cells cope with unfolded proteins during ERS [38]. Notably, prolonged ERS was also found to cause cell apoptosis and GRP78 downregulation, while L-glutamine maintained the level of expression of GRP78 and alleviated the ERS-induced apoptosis, suggesting that the high level of GRP78 maintained by L-glutamine may contribute to its anti-apoptotic effect in ERS-responsive cells. L-glutamine may also affect cell apoptosis by acting as the energy substrate in the body's response to ERS, thereby maintaining a high level of GRP78. To test this possibility, we replaced L-glutamine with its intermediate product $\alpha$-ketoglutarate, which plays a functional role in promoting energy metabolism; the AKG replacement did not alleviate the ERS-induced apoptosis (data not shown). Hence, we proposed that L-glutamine may alleviate ERS-induced apoptosis by activating UPR signalling and thereby maintaining the GRP78 level.

The UPR consists of three main signalling branches: PERK, IRE1 $\alpha$, and ATF- 6 . Prolonged or uncontrolled ERS results in apoptosis [39]. The most important pro-apoptotic pathway in response to ERS has been shown to involve the triggering by PERK of the transcription factor CHOP/GADD153 [40]. Similarly, we found that TUNI treatment increased apoptosis in IPEC-J2 while upregulating GADD153 expression. The response to apoptosis depends on both the condition of the cells and the context of the stress. Our results demonstrated that L-glutamine markedly downregulated the expression of GADD153, suggesting that L-glutamine may decrease PERK pathway mediated apoptosis in ERS-responsive cells. To identify the mechanism of ERS-induced apoptosis, the levels of PERK and p-PERK were determined; however, L-glutamine had little effect on the expression or phosphorylation of PERK. Multiple regulatory modes of GADD153 are likely to exist, due to the downstream genetic activity ofIRE1 $\alpha$ and XBP-1s-dependent actions.

When unfolded proteins accumulate in the ER, IRE1 $\alpha$ is activated by autophosphorylation and oligomerisation, triggering RNase activity [28]. As well as inducing XBP1 splicing activity, the activated IRE1 also preferentially degrades ER-related mRNA by cutting at both stem-loop sites and non-stem-loop sites, which is called regulated IRE1 dependent decay (RIDD) [41]. RIDD is made more effective by the silencing of XBP1 splicing [42]. These two processes are thought to reduce the folding load of nascent proteins in the ER and maintain ER homeostasis. Similarly, the results obtained in this study revealed that IRE1 $\alpha$ and XBP1s are highly upregulated by L-glutamine in cells responding to prolonged ERS, suggesting that upregulated XBP-1 splicing, not RIDD, is the key signalling mechanism involved in L-glutamine regulated cell survival. To the best of our knowledge, this is the first study to provide evidence of the contribution of L-glutamine to the activation of the IRE1 $\alpha$-XBP1 axis. DOX has been shown to inhibit the IRE1 $\alpha$-XBP1 axis in the HT1080 and RPMI8226 cell lines, and high doses of DOX have been found to threaten cell survival [43]. Consistent with previous reports, the results reported here showed that DOX inhibits the expression of IRE1 $\alpha$-XBP1s in the ERS-responsive cell line IPEC-J2 in a dose-independent manner. However, diverging from previous findings, increasing the concentration of DOX from 1 to $5 \mu \mathrm{g} \mathrm{mL} \mathrm{g}^{-1}$ was found to have little 
adverse effect on cell survival within the untriggered ERS milieu. This difference may be due to the cultural milieu used in our study (basic DMEM vs. DMEM with $10 \%$ fetal calf serum (FCS) in the relevant previous study) and differences in the sensitivity of cell types to DOX treatment. To identify the anti-apoptotic mechanism of L-glutamine, we optimised the inhibition of XBP-1s by introducing $5 \mu \mathrm{g} \mathrm{mL}{ }^{-1}$ of DOX to inhibit the IRE1 $\alpha$-XBP1 axis. Our results clearly demonstrated that the specific inhibition of IRE1 $\alpha$-XBP1 by $5 \mu \mathrm{g} \mathrm{mL} \mathrm{m}^{-1}$ of DOX eliminated the anti-apoptotic effect of L-glutamine. This finding strongly suggests that IRE1 $\alpha-\mathrm{XBP} 1$ upregulation is not a consequence of cell survival but actively helps cells to survive. A working model of the role of L-glutamine in protecting ERS-responsive intestinal cells from apoptosis is provided in Figure 7.

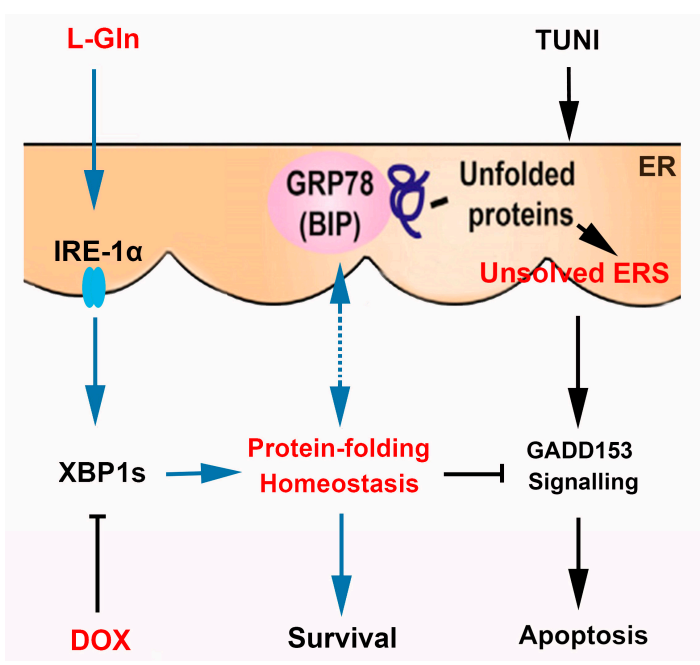

Figure 7. A working model of the role of L-glutamine in protecting an intestinal cell from apoptosis in response to prolonged ERS.

\section{Materials and Methods}

\subsection{Reagents}

Dulbecco's modified Eagle medium (DMEM), foetal bovine serum (FBS) and antibiotics (penicillin and streptomycin) required for the cell cultures were obtained from GIBCO (Carlsbad, CA, USA). The cell culture plates were manufactured by Corning Inc. (Corning, NY, USA). The CCK-8 and DAPI working solution were purchased from Beyotime Biotechnology (Shanghai, China). L-glutamine, tunicamycin (TUNI), doxorubicin (DOX) and dimethylsulfoxide (DMSO) were purchased from Sigma (Saint Louis, MO, USA). The antibodies against XBP-1s and phospho-PERK were obtained from Santa Cruz Biotechnology, and the antibodies against PERK, ATF6, IRE1 $\alpha$, GRP78, CHOP/GADD153, ATF4 cleaved- caspase3, and $\beta$-actin, plus the Alexa Fluor 488-conjugated secondary antibodies, were obtained from Abcam (Cambridge, MA, USA).

\subsection{Cell Culture and Treatments}

The IPEC-J2 cells were grown in DMEM containing 10\% FBS, $50 \mu \mathrm{g} \mathrm{mL} \mathrm{m}^{-1}$ penicillin and $50 \mu \mathrm{g} \mathrm{mL}{ }^{-1}$ streptomycin (a normal growth medium). They were seeded on six-well plates (Corning) at a density of 100,000 cells per well for $36 \mathrm{~h}$. Before the treatments, the cells were washed with phosphate buffered saline (PBS) and the growth culture medium was replaced with basic DMEM without FBS or L-glutamine. First, we treated cells with DMSO, $1 \mu \mathrm{g} \mathrm{mL}{ }^{-1}$ TUNI/DMSO and $0.45 \mathrm{~g} \mathrm{~L}^{-1}$ L-glutamine /DMSO or a TUNI/L-glutamine combination to investigate the molecular mechanism underlying L-glutamine's regulation of ERS and the effects of this process. The most appropriate concentration of L-glutamine $\left(0.45 \mathrm{~g} \mathrm{~L}^{-1}\right)$ in the treatments was determined in a pre-experiment. Based on the results of our pre-experiment with IRE1 $\alpha$ pathway inhibition, we treated cells with DMSO, TUNI/L-glutamine 
and TUNI/L-glutamine /DOX. We used the DMSO to dilute the TUNI, doxorubicin and L-glutamine, with an equal amount of DMSO added in the control group. We determined through preliminary experiments that exposure to $1.0 \mu \mathrm{g} \mathrm{mL} \mathrm{L}^{-1}$ TUNI and $5 \mu \mathrm{M}$ doxorubicin for $24 \mathrm{~h}$ represented the most appropriate treatment for the generation of ERS-induced apoptosis and IRE1 $\alpha$ pathway inhibition.

\subsection{Cell Viability Assay}

Cell viability was assessed using the CCK-8. The effective component of the CCK-8 is Dojindo's highly water-soluble tetrazolium salt, WST-8, which can be reduced by dehydrogenase activities in cells to give a yellow formazan dye. The absorbance of each well below $450 \mathrm{~nm}$ was taken to indicate the number of living cells. Briefly, cells were seeded in a 96-well plate and incubated with their respective treatments. After a specific duration $(0,8,16,24$, or $36 \mathrm{~h})$, the cells were incubated with $20 \mu \mathrm{L} \mathrm{CCK}-8$ for $3 \mathrm{~h}$ at $37^{\circ} \mathrm{C}$. Subsequently, the absorbance was read at $450 \mathrm{~nm}$ using a microplate reader (Bio-Rad Laboratories, Veenendaal, The Netherlands).

\subsection{Cell Proliferation Determination by EdU Staining}

DNA synthesis during cell proliferation in each group was quantified by incorporating EdU (Invitrogen, Carlsbad, CA, USA) using a Cell-lightTM EdU Kit (Rui Bo Biotechnology Limited Company, Guangzhou, China), as described in our previous studies. Initially, IPEC-J2 cells were cultured in DMEM containing $50 \mu \mathrm{M}$ EdU for $1 \mathrm{~h}$. A Leica DMI4000B microscope (LEICA, Wetzlar, Germany) was used to capture an image of EdU-positive cells counter-stained with Apollo ${ }^{\circledR} 567$ fluorochrome (Invitrogen, Carlsbad, CA, USA). The percentage of EdU-positive cells was expressed as the ratio of cells with red nuclei in at least five separate microscopic fields randomly selected for counting.

\subsection{Flow Cytometry Analysis}

Following the treatments, the cells were collected and their apoptotic behaviour was studied by flow cytometry, using an Annexin V-FITC Apoptosis Detection Kit (Beyotime Biotechnology, Shanghai, China) according to the manufacturer's instructions. Data acquisition and analysis were performed using the flow cytometry system and CELL Quest software (BD Biosciences, Franklin, NJ, USA). Statistical analysis of mortality and apoptosis rates was performed using Prism v5.0 software (GraphPad Software, San Diego, CA, USA) based on the output of the flow cytometry.

\subsection{Western Blot Analysis}

After the treatments, the cells were washed three times in PBS. The resulting samples were lysed for $10 \mathrm{~min}$ in an ice-cold buffer with a complete protease inhibitor cocktail, and immunoblotting assays were performed as previously described [44]. The blots were examined using the ECL Plus detection system (Thermo, Waltham, MA, USA) under the conditions recommended by the manufacturer, before signals were visualised using Fujifilm (LAS-3000; Fuji, Tokyo, Japan). The protein band densities were normalised to the specific loading control protein band ( $\beta$-actin, total PERK) and quantified using Quantity One software (Bio-Rad, Hercules, CA, USA).

\subsection{Immunofluorescence}

The cells were fixed and permeabilised with cold $100 \%$ methanol for $10 \mathrm{~min}$ on ice. They were then treated with $4 \mathrm{~N} \mathrm{HCl}$ for $10 \mathrm{~min}$ for staining, followed by exposure to $1.5 \mathrm{M}$ Tris- $\mathrm{HCl}$ ( $\mathrm{pH}$ 8.8) for $10 \mathrm{~min}$, before being blocked with $10 \%$ goat serum. The cells were incubated overnight at $4{ }^{\circ} \mathrm{C}$ with primary anti-GRP78 rabbit polyclonal antibodies. This was followed by incubation for $1 \mathrm{~h}$ with Alexa Fluor 488-conjugated secondary antibodies (Life Technologies, Waltham, MA, USA). The nucleuses were incubated with DAPI working solution for $5 \mathrm{~min}$ before fluorescence detection. The images were captured using a laser confocal microscope (LEICA, Solms, Germany). 


\subsection{Statistical Analysis}

Mean values \pm SDs were calculated using Excel 2010 (Microsoft, Seattle, WA, USA) for each of the three independent experiments. The statistical analysis (one-way analysis of variance) was performed using Prism v5.0 software (GraphPad Software, San Diego, CA, USA). This was followed by Bonferroni multiple comparisons and post hoc analysis. Differences between the treatments were considered statistically significant at $p \leq 0.01(* *)$ or $p \leq 0.05\left({ }^{*}\right)$.

\section{Conclusions}

Our results suggest that L-glutamine protects IPEC-J2 from ERS-induced apoptosis via the IRE1 $\alpha$-XBP1 axis, indicating that the L-glutamine-activated IRE1 $\alpha-X B P 1$ axis is crucial to the maintenance of ER homeostasis. These findings provide novel insights into the activity of L-glutamine as a mechanism connecting ERS with intestinal health, and may contribute to a better understanding of intestinal homeostasis.

Acknowledgments: We thank National Engineering Laboratory for Pollution Control and Waste Utilization in Livestock and Poultry Production, and all the members participated in this trial. This work was supported by the National Science Foundation for Distinguished Young Scholars of Hunan Province (2016JJ1015); Key Programs of frontier scientific research of the Chinese Academy of Sciences, the National Basic Research Program of China (2013CB127306); the Open Foundation of Key Laboratory of Agro-ecological Processes in Subtropical Region, Institute of Subtropical Agriculture, Chinese Academy of Sciences (ISA2016101); the Chinese Academy of Sciences "Hundred Talent" award; and the National Natural Science Foundation Project (31472107).

Author Contributions: The following statements should be used "Q.J., K.Y. and Y.Y. conceived and designed the experiments; Q.J. and J.C. performed the experiments; Q.J., S.L. and K.Y. analyzed the data; G.L. contributed reagents/materials/analysis tools; Q.J. and G.L. wrote the paper."

Conflicts of Interest: The authors declare no conflict of interest.

\section{Abbreviations}

$\begin{array}{ll}\text { ERS } & \text { Endoplasmic reticulum stress } \\ \text { TUNI } & \text { Tunicamycin } \\ \text { GRP78 } & \text { Glucose-regulated protein } 78 \\ \text { CHOP } & \text { C/enhancer binding protein homologous protein } \\ \text { IPEC-J2 } & \text { Intestinal porcine epithelial cell line J2 } \\ \text { DOX } & \text { Doxorubicin }\end{array}$

\section{References}

1. Xing, S.; Zhang, B.L.; Lin, M.; Zhou, P.; Li, J.L.; Zhang, L.; Gao, F.; Zhou, G.H. Effects of alanyl-glutamine supplementation on the small intestinal mucosa barrier in weaned piglets. Asian-Australas. J. Anim. Sci. 2017, 30, 236-245. [CrossRef] [PubMed]

2. Li, J.Y.; Lu, Y.; Hu, S.; Sun, D.; Yao, Y.M. Preventive effect of glutamine on intestinal barrier dysfunction induced by severe trauma. World J. Gastroenterol. 2002, 8, 168-171. [CrossRef] [PubMed]

3. Sands, S.; Ladas, E.J.; Kelly, K.M.; Weiner, M.; Lin, M.; Ndao, D.H.; Dave, A.; Vahdat, L.T.; Bender, J.G. Glutamine for the treatment of vincristine-induced neuropathy in children and adolescents with cancer. Support. Care Cancer 2017, 25, 701-708. [CrossRef] [PubMed]

4. De Sena, J.I.N.; Guimaraes, S.B.; de Vasconcelos, P.R.L. Metabolic changes induced by pre-administration of 1-alanyl-glutamine and omega-3 in wistar rats subjected to sepsis. Acta Cirurgica Brasileira 2010, 25, 529-534. [CrossRef]

5. Fan, J.; Wu, J.; Wu, L.D.; Li, G.P.; Xiong, M.; Chen, X.; Meng, Q.Y. Effect of parenteral glutamine supplementation combined with enteral nutrition on HSP90 expression and lymphoid organ apoptosis in severely burned rats. Burns 2016, 42, 1494-1506. [CrossRef] [PubMed]

6. Johnson, I.R.; Ball, R.O.; Baracos, V.E.; Field, C.J. Glutamine supplementation influences immune development in the newly weaned piglet. Dev. Comp. Immunol. 2006, 30, 1191-1202. [CrossRef] [PubMed] 
7. Zhu, Y.H.; Lin, G.; Dai, Z.L.; Zhou, T.J.; Li, T.T.; Yuan, T.L.; Wu, Z.L.; Wu, G.Y.; Wang, J.J. L-glutamine deprivation induces autophagy and alters the mtor and mapk signaling pathways in porcine intestinal epithelial cells. Amino Acids 2015, 47, 2185-2197. [CrossRef] [PubMed]

8. Zhang, B.L.; Lin, M.; Yu, C.N.; Li, J.L.; Zhang, L.; Zhou, P.; Yang, W.W.; Gao, F.; Zhou, G.H. Alanyl-glutamine supplementation regulates mtor and ubiquitin proteasome proteolysis signaling pathways in piglets. Nutrition 2016, 32, 1123-1131. [CrossRef] [PubMed]

9. Yi, D.; Hou, Y.Q.; Wang, L.; Ouyang, W.J.; Long, M.H.; Zhao, D.; Ding, B.Y.; Liu, Y.L.; Wu, G.Y. L-glutamine enhances enterocyte growth via activation of the mtor signaling pathway independently of ampk. Amino Acids 2015, 47, 65-78. [CrossRef] [PubMed]

10. Paschen, W.; Frandsen, A. Endoplasmic reticulum dysfunction-A common denominator for cell injury in acute and degenerative diseases of the brain? J. Neurochem. 2001, 79, 719-725. [CrossRef] [PubMed]

11. Duvigneau, J.C.; Miller, I.; Bahrami, S.; Redl, H.; Kozlov, A.V. ER stress markers in inflammation and ischemia. Inflamm. Res. 2010, 59, S157.

12. McGuckin, M.A.; Eri, R.D.; Das, I.; Lourie, R.; Florin, T.H. Intestinal secretory cell ER stress and inflammation. Biochem. Soc. Trans. 2011, 39, 1081-1085. [CrossRef] [PubMed]

13. McGuckin, M.A.; Eri, R.D.; Das, I.; Lourie, R.; Florin, T.H. Er stress and the unfolded protein response in intestinal inflammation. Am. J. Physiol.-Gastrointest. Liver Physiol. 2010, 298, G820-G832. [CrossRef] [PubMed]

14. Ma, A. Unresolved er stress inflames the intestine. Cell 2008, 134, 724-725. [CrossRef] [PubMed]

15. Hetz, C.; Papa, F.R. The Unfolded Protein Response and Cell Fate Control. Mol. Cell 2017, 17, S1097-S2765. [CrossRef] [PubMed]

16. Fernandez, A.; Ordonez, R.; Reiter, R.J.; Gonzalez-Gallego, J.; Mauriz, J.L. Melatonin and endoplasmic reticulum stress: Relation to autophagy and apoptosis. J. Pineal Res. 2015, 59, 292-307. [CrossRef] [PubMed]

17. Rashid, H.O.; Yadav, R.K.; Kim, H.R.; Chae, H.J. ER stress: Autophagy induction, inhibition, and selection. Autophagy 2015, 11, 1956-1977. [CrossRef] [PubMed]

18. Ron, D.; Hubbard, S.R. How IRE1 reacts to ER stress. Cell 2008, 132, 24-26. [CrossRef] [PubMed]

19. Crespo, I.; San Miguel, B.; Prause, C.; Marroni, N.; Cuevas, M.J.; Culebras, J.; Gonzalez-Gallego, J.; Tunon, M.J. Glutamine treatment attenuates endoplasmic reticulum stress and inflammation in TNBS-induced colitis. PLoS ONE 2012, 7, e50407. [CrossRef] [PubMed]

20. Jiang, Q.; Chen, S.; Ren, W.K.; Liu, G.; Yao, K.; Wu, G.Y.; Yin, Y.L. Escherichia coli aggravates endoplasmic reticulum stress and triggers CHOP-dependent apoptosis in weaned pigs. Amino Acids 2017, 49, 2073-2082. [CrossRef] [PubMed]

21. Ringseis, R.; Kynast, A.M.; Couturier, A.; Most, E.; Eder, K. Ingestion of frying fat leads to activation of the endoplasmic reticulum stress-induced unfolded protein response in the duodenal mucosa of pigs. Mol. Nutr. Food Res. 2016, 60, 957-963. [CrossRef] [PubMed]

22. Zakrzewski, S.S.; Richter, J.F.; Krug, S.M.; Jebautzke, B.; Lee, I.F.; Rieger, J.; Sachtleben, M.; Bondzio, A.; Schulzke, J.D.; Fromm, M.; et al. Improved cell line IPEC-J2, characterized as a model for porcine jejunal epithelium. PLoS ONE 2013, 8, e79643. [CrossRef] [PubMed]

23. Zhang, W.; Zhu, Y.H.; Yang, J.C.; Yang, G.Y.; Zhou, D.; Wang, J.F. A selected lactobacillus rhamnosus strain promotes egfr-independent akt activation in an enterotoxigenic Escherichia coli K88-infected IPEC-J2 cell model. PLoS ONE 2015, 10, e0125717. [CrossRef] [PubMed]

24. Yang, F.J.; Wang, A.N.; Zeng, X.F.; Hou, C.L.; Liu, H.; Qiao, S.Y. Lactobacillus reuteri i5007 modulates tight junction protein expression in IPEC-J2 cells with LPS stimulation and in newborn piglets under normal conditions. BMC Microbiol. 2015, 15. [CrossRef] [PubMed]

25. Paszti-Gere, E.; Barna, R.F.; Kovago, C.; Szauder, I.; Ujhelyi, G.; Jakab, C.; Meggyeshazi, N.; Szekacs, A. Changes in the distribution of type II transmembrane serine protease, tmprss2 and in paracellular permeability in IPEC-J2 cells exposed to oxidative stress. Inflammation 2015, 38, 775-783. [CrossRef] [PubMed]

26. Bauchart-Thevret, C.; Cui, L.; Wu, G.; Burrin, D.G. Arginine-induced stimulation of protein synthesis and survival in IPEC-J2 cells is mediated by mtor but not nitric oxide. Am. J. Physiol. Endocrinol. Metab. 2010, 299, E899-E909. [CrossRef] [PubMed]

27. Wang, H.; Zhang, C.; Wu, G.Y.; Sun, Y.L.; Wang, B.; He, B.B.; Dai, Z.L.; Wu, Z.L. Glutamine enhances tight junction protein expression and modulates corticotropin-releasing factor signaling in the jejunum of wean ling piglets. J. Nutr. 2015, 145, 25-31. [CrossRef] [PubMed] 
28. Kaser, A.; Lee, A.H.; Franke, A.; Glickman, J.N.; Zeissig, S.; Tilg, H.; Nieuwenhuis, E.E.S.; Higgins, D.E.; Schreiber, S.; Glimcher, L.H.; et al. XBP1 links er stress to intestinal inflammation and confers genetic risk for human inflammatory bowel disease. Cell 2008, 134, 743-756. [CrossRef] [PubMed]

29. Rhoads, J.M.; Keku, E.O.; Woodard, J.P.; Bangdiwala, S.I.; Lecce, J.G.; Gatzy, J.T. L-glutamine with d-glucose stimulates oxidative-metabolism and nacl absorption in piglet jejunum. Am. J. Physiol. 1992, 263, G960-G966. [PubMed]

30. Pardo, L.P.; Poveda, P.A.; da Silva, C.; dos Santos, A.; Venancio, E.; Arantes, V.; Nogueira, E. Effect of L-glutamine levels in piglets diets challenged with escherichia coli lipopolysacharides. Revista MVZ Córdoba 2014, 19, 4328-4337. [CrossRef]

31. Molino, J.P.; Donzele, J.L.; de Oliveira, R.F.M.; Saraiva, A.; Haese, D.; Fortes, E.I.; de Souza, M.F. L-glutamine and L-glutamate in diets with different lactose levels for piglets weaned at 21 days of age. Revista Brasileira de Zootecnia 2012, 41, 98-105. [CrossRef]

32. Kim, S.Y.; Hwang, J.S.; Han, I.O. Tunicamycin inhibits toll-like receptor-activated inflammation in raw 264.7 cells by suppression of nf-kappa 13 and c-jun activity via a mechanism that is independent of er-stress and n-glycosylation. Eur. J. Pharmacol. 2013, 721, 294-300. [CrossRef] [PubMed]

33. Bae, E.Y.; Lee, S.W.; Seong, S.; Cho, W.; Ahn, J.S.; Cho, H.S. Inhibitory effects of verrucarin a on tunicamycin-induced er stress in fao rat liver cells. Molecules 2015, 20, 8988-8996. [CrossRef] [PubMed]

34. Costa, R.O.; Ferreiro, E.; Cardoso, S.M.; Oliveira, C.R.; Pereira, C.M.F. ER stress-mediated apoptotic pathway induced by a $\beta$ peptide requires the presence of functional mitochondria. J. Alzheimers Dis. 2010, 20, 625-636. [CrossRef] [PubMed]

35. Taishiro, J.; Kikuchi, S.; Shinpo, K.; Kishirnoto, R.; Tsuji, S.; Sasaki, H. Role of p53 in neurotoxicity induced by the endoplasmic reticulum stress agent tunicamycin in cultures of rat organotypic slice spinal cord. J. Neurosci. Res. 2007, 85, 395-401. [CrossRef] [PubMed]

36. Suganya, N.; Bhakkiyalakshmi, E.; Suriyanarayanan, S.; Paulmurugan, R.; Ramkumar, K.M. Quercetin ameliorates tunicamycin-induced endoplasmic reticulum stress in endothelial cells. Cell Prolif. 2014, 47, 231-240. [CrossRef] [PubMed]

37. Nakayama, H.; Shimoke, K.; Isosaki, M.; Satoh, H.; Yoshizumi, M.; Ikeuchi, T. Comprison of polyglutamine-, tunicamycin- and thapsigargin-induced er stress in pc12 cells. J. Pharmacol. Sci. 2006, 100, 107.

38. Wang, C.; Jiang, K.; Gao, D.M.; Kang, X.N.; Sun, C.; Zhang, Q.L.; Li, Y.; Sun, L.; Zhang, S.; Guo, K.; et al. Clusterin protects hepatocellular carcinoma cells from endoplasmic reticulum stress induced apoptosis through grp78. PLoS ONE 2013, 8, e55981. [CrossRef] [PubMed]

39. Rizvi, S.H.M.; Parveen, A.; Ahmad, I.; Ahmad, I.; Arshad, M.D.; Verma, A.K.; Mahdi, A.A. Aluminum induces er stress-mediated neuro-inflammation in human neuroblastoma SH-SY5Y cells: Implication of oxidative stress and apoptosis. Int. J. Toxicol. 2016, 35, 54-55.

40. Yao, S.T.; Tian, H.; Miao, C.; Zhang, D.W.; Zhao, L.; Li, Y.Y.; Yang, N.N.; Jiao, P.; Sang, H.; Guo, S.D.; et al. D4f alleviates macrophage-derived foam cell apoptosis by inhibiting CD36 expression and er stress-chop pathway. J. Lipid Res. 2015, 56, 836-847. [CrossRef] [PubMed]

41. Cubillos-Ruiz, J.R.; Silberman, P.C.; Rutkowski, M.R.; Chopra, S.; Perales-Puchalt, A.; Song, M.; Zhang, S.; Bettigole, S.E.; Gupta, D.; Holcomb, K.; et al. ER stress sensor XBP1 controls anti-tumor immunity by disrupting dendritic cell homeostasis. Cell 2015, 161, 1527-1538. [CrossRef] [PubMed]

42. Maurel, M.; Chevet, E.; Tavernier, J.; Gerlo, S. Getting RIDD of RNA: IRE1 in cell fate regulation. Trends Biochem. Sci. 2014, 39, 245-254. [CrossRef] [PubMed]

43. Jiang, D.D.; Lynch, C.; Medeiros, B.C.; Liedtke, M.; Bam, R.; Tam, A.B.; Yang, Z.F.; Alagappan, M.; Abidi, P.; Le, Q.T.; et al. Identification of doxorubicin as an inhibitor of the IRE1 $\alpha$-xbp1 axis of the unfolded protein response. Sci. Rep. 2016, 6, 33353. [CrossRef] [PubMed]

44. Jiang, Q.; He, L.Q.; Hou, Y.Q.; Chen, J.S.; Duan, Y.H.; Deng, D.; Wu, G.Y.; Yin, Y.L.; Yao, K. $\rho$-ketoglutarate enhances milk protein synthesis by porcine mammary epithelial cells. Amino Acids 2016, 48, 2179-2188. [CrossRef] [PubMed]

(C) 2017 by the authors. Licensee MDPI, Basel, Switzerland. This article is an open access article distributed under the terms and conditions of the Creative Commons Attribution (CC BY) license (http://creativecommons.org/licenses/by/4.0/). 